\title{
The effects of matrix module structure on shipyard panel line's throughput
}

\author{
Murat Ozkok, Ph.D. \\ Karadeniz Technical University, Trabzon, Turkey
}

\begin{abstract}
Over the last decades a really tough competitive environment has been observed in shipbuilding sector. Under these circumstances shipyards desire to reduce product cycle time in order to manufacture the product as soon as possible. For this reason it is required to make some alterations in shipyard production system in order to reduce cycle time. In this study a panel fabrication line used in a shipyard, has been considered. The workstations of the panel line have been modeled by using ARENA simulation software and the effects of matrix module assembly on panel line throughput, have been determined.
\end{abstract}

Key words: shipyard; ship production; panel line; matrix module assembly; simulation

\section{INTRODUCTION}

In recent years there is a hard competitive environment in many industry branches including shipyard industry. In order to increase their competitiveness shipyards have to consider the factors affecting competitiveness according to Rashwan and Naguib [1]. One of the factors is delivery time. To be able to keep the competitive power, the companies have to deliver the products to their customers on time and reduce the production cycle time. For this reason the companies have to investigate their production systems and improve their processes. In order to see the effects of the improvements on a real system, simulation tool is mostly used.

In this study simulation is used as an optimization tool. Simulation is used to understand character of real systems. There are many simulation applications in shipbuilding, as described in the literature. In a common study realized by Michigan University and Seoul National University, the whole processes of a shipyard are attempted to be modeled with simulation and the effects of some changes on the system are perceived [2]. In the study of Okumoto et al. [3], performed by modeling the scaffold placement with three-dimensional simulation CAD system, the effects of the changes on the system have been observed. Shin [4] has modelled the workstations of the subassembly line with the use of simulation and determined the effect of placing a welding robot on productivity. In the other study of Shin [5] an optimum shipbuilding layout has been found by using simulation. Alfeld et al. [6] has used a special software in simulating the shipyard processes to ensure that the planners take decisions easily. Alkaner [7] has simulated the processes of the profile cutting station and by making some changes in resources, the effects of these changes have been investigated. Doing some alterations on panel production station, Greenwood et al. [8] has investigated the effects of the changes on the production system. Lee et al. [9] has found the effects of the intelligent welding robot system on welding performance. Cha and Roh [10] have developed a simulation framework and applied it to block erection process. As can be concluded, there are many application fields of simulation in shipyard industry.

In this study the processes of the panel line of a shipyard located in Turkey have been considered. Firstly, the detailed process analysis of the panel line has been performed. In this way the whole work activities of the panel line and their durations have been found. In the second stage of the study the simulation model of the panel line has been elaborated by using ARENA 11.0 software. The required data achieved from the process analysis have been put in the simulation model. Then the model has been run for 10-day period and number of products manufactured by the panel line has been determined. In the third stage of the study an alteration in section spot welding station has been made. And, this alteration has been put in the simulation model and the model has been run again for 10- day period. Then the effect of this alteration on the system throughput has been determined.

As mentioned above, the alteration made in the panel line is interesting in the case of section spot welding station. In the section spot welding station of the panel line, minor and sub- assemblies are mounted on the flat panel assembly and their matrix structure is formed. In many shipyards in Turkey, minor and sub-assemblies are welded one by one on flat panel assembly in order to produce matrix structure. In this way it takes a longer time to manufacture the matrix structure and a bottleneck situation may occur on the panel line. Instead of 
the mounting of minor and sub-assemblies one by one, they should be mounted on flat panel assembly as a module. In other words, the matrix structure can be mounted as a module. It is believed that mounting the matrix structure as a module reduces the production cycle time and increases the throughput of the panel line.

\section{METHODOLOGY}

In this study, the steps presented in Fig 1 are followed, respectively. At the beginning the workstations forming the panel line are determined and defined (Step 1). Then the product to be manufactured in the panel line and its subcompenents are defined (Step 2). After the process analysis of the workstations is performed, the panel line is modelled by using simulation (Model 1), (Step 4) and the model is run for a specified duration time (Step 5). In Step 6, work flow in the section spot welding is changed and module mounting is carried out instead of mounting the minor and sub-assemblies one by one on the flat panel assembly (Stage F). In Step 7, the panel line is modelled by using simulation again and consequently Model 2 is achieved. In Model 2, the workstations' work flows remain constant except for the section spot welding. In Step 8, Model 2 is run for the same time period as in the case of Model 1 and throughput quantity of the panel line is achieved. At the last step (Step 9), Model 1 and Model 2 are compared mutually in terms of throughput quantity.

Determination of panel line workstations (Step 1)

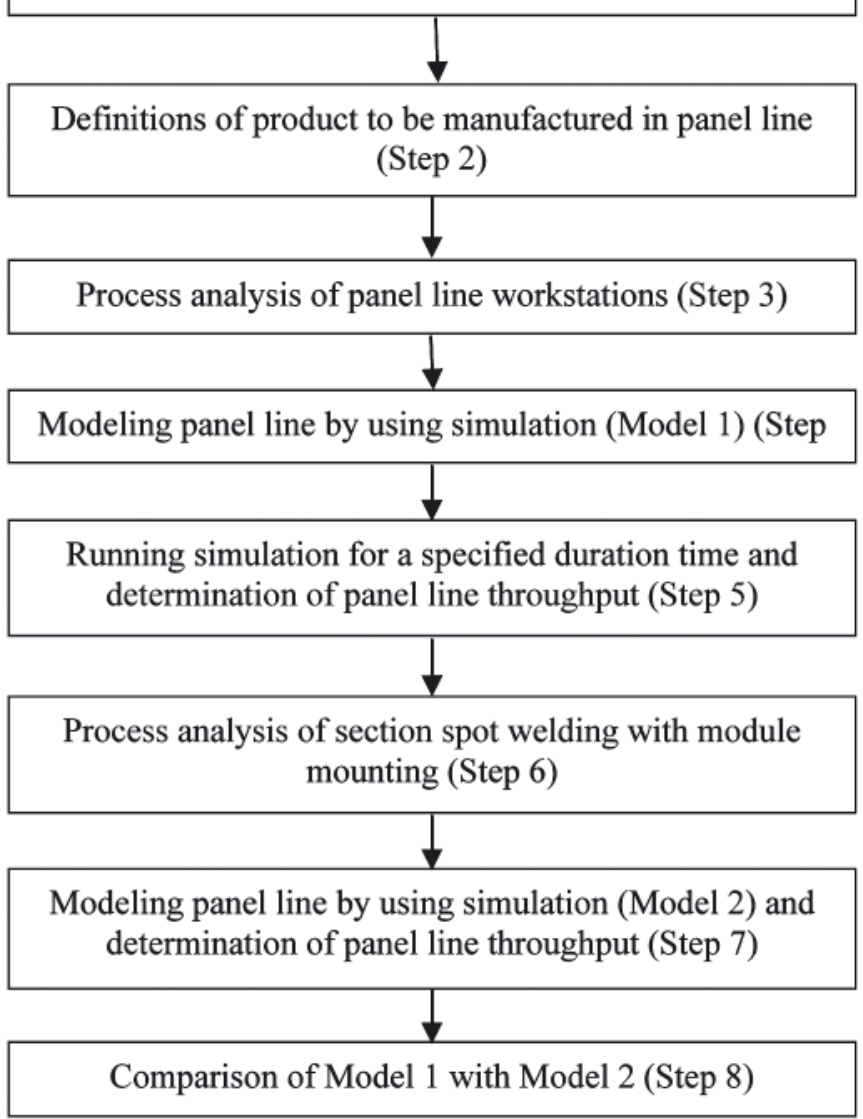

Fig. 1. Methodology of the study

\section{Determination of panel line workstations (Step 1)}

The panel line is a production cell where flat structures are fabricated. It consists of different types of workstations. There are 9 workstations on the panel line. Each workstation has a function in the production process. Tab. 1 shows the workstations located on the panel line.

Tab. 1. Workstations on the panel line

\begin{tabular}{|c|c|}
\hline $\begin{array}{c}\text { No. of } \\
\text { workstation }\end{array}$ & Workstation name \\
\hline I1 & Edge cutting station \\
\hline I2 & Edge cleaning and sequencing \\
\hline I3 & Panel production \\
\hline I4 & Panel cutting \\
\hline I5 & Profile spot welding \\
\hline I6 & Profile tig welding \\
\hline I7 & Section spot welding tig welding \\
\hline I8 & Grinding \\
\hline I9 & \\
\hline
\end{tabular}

The edge cutting operations of the plates are performed in the edge cutting station (I1). The cutting operation is carried out by using plasma. The plates being cut are then sent to the edge cleaning and sequencing station (I2) where the edge cleaning operation of the cut surfaces is performed. Grinding machines are used in this operation. The sequencing operation is also carried out in this station in order to sequence the plates which enter the panel production machine. The plates are then sent to the panel production station from the edge cutting and sequencing station. In the panel production station (I3), the plates are mounted by using submerged arc welding. As an output of this station a panel is produced and then it goes to the panel cutting station where inside and outside cutting operations of the panel are performed. In the panel cutting station (I4), marking operation is also done. The cut and marked panel is sent to the profile spot welding station (I5). Here, the profiles are mounted on the flat panel and a flat panel assembly is produced as an output. a spot welding machine is used for this operation. The flat panel assembly is then sent to the profile tig welding station (I6) in order to complete the welding operations. After completion of the welding operation of the flat panel assembly it goes to the section spot welding station (I7) where minor assemblies and sub - assemblies are mounted on the flat panel assembly by using spot welding. As an output, a major sub-assembly is manufactured in this station. The major sub-assembly is sent to the section tig welding station (I8) from the section spot welding station in order to complete the welding operation. Finally, the major sub-assembly arrives at the grinding station, the last workstation of the panel line (I9). In this station the grinding operations of the welded places of the major subassembly are carried out. After completion of the grinding operations it leaves the panel line. Fig. 2 shows the material flow on the panel line.

\section{Definitions of products to be manufactured in panel line (Step 2)}

In the panel line interim products which have flat structure are produced. For a double bottom block, flat panel assembly and major sub-assembly are fabricated in the panel line. In this study, a major sub-assembly was considered as a product.

In ship production some codes, each representing a production stage of blocks, are used. Such coding system is very useful to seperate and check the production stages orderly. Tab. 2 shows the production stages and their definition. 


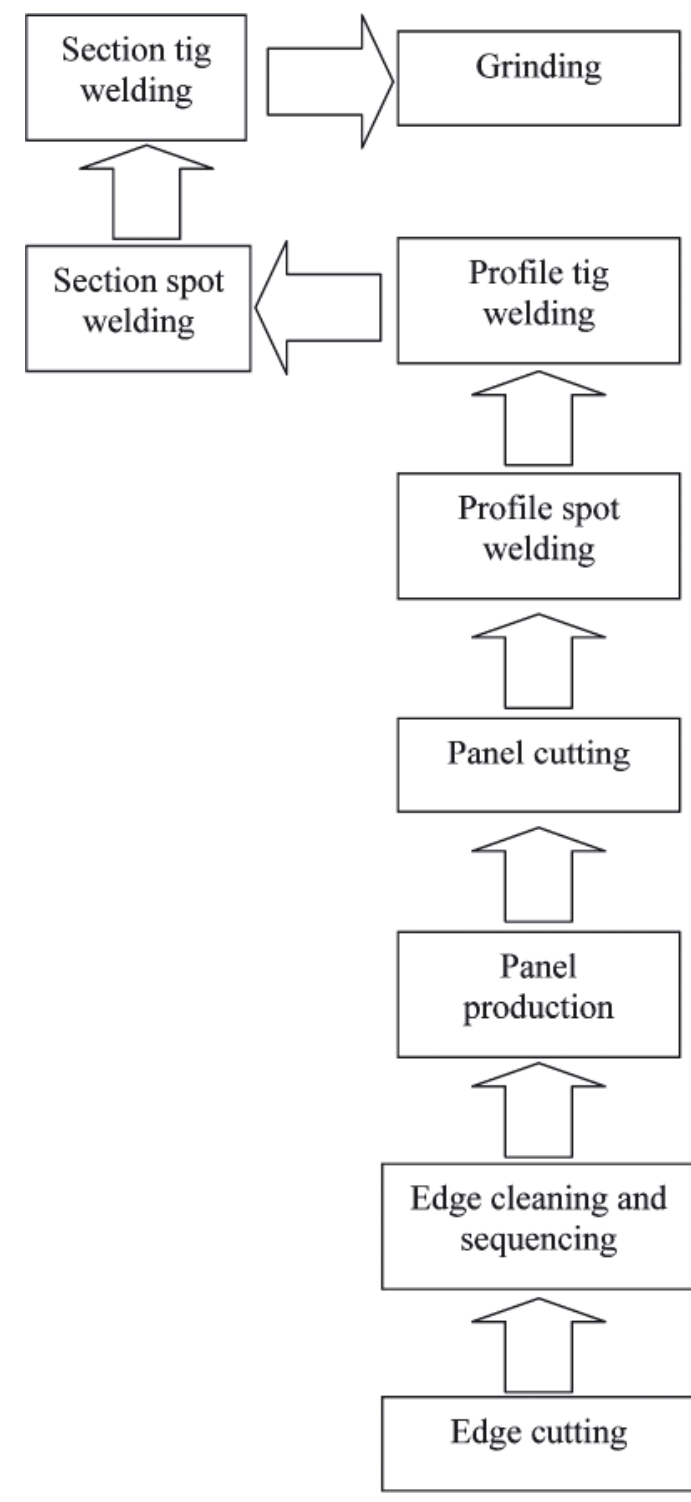

Fig. 2. Work flow through the panel line

The major sub-assembly (Stage G) is regarded as a throughput of the panel line in question and it includes structures of various types, such as single section parts (Stage A), single plate parts (Stage B), minor assemblies (Stage C), sub-assemblies (Stage D), flat plate assembly (Stage E), and flat panel assembly (Stage F), as defined in Tab. 2.

The single section parts and single plate parts which have specified dimensions are described as a and B production stages, respectively. a single profile is defined as a production stage and a single plate is defined as B production stage.

If one single section part and one single plate part are assembled together, the minor assembly (C) is manufactured. If two or more minor assemblies are fitted together the subassembly (D) is built.

The flat plates constitute flat panel structures. If two or more flat plates are fitted together they form the flat plate assembly (E). If single section parts (A) are fitted onto the panel, the panel with profiles, called the flat plane assembly $(\mathrm{F})$, is formed.

Minor and sub-assemblies ( $\mathrm{C}$ and $\mathrm{D}$ production stages) are fitted onto the flat panel assembly $(\mathrm{F})$ to form finally the major sub-assembly (G).

As above mentioned, the major sub-assembly includes various types of production stages. Fig. 3 shows the product breakdown structure of the major sub-assembly considered in this study.
Tab. 2. Production stages and definitions

\begin{tabular}{|c|c|c|}
\hline $\begin{array}{c}\text { Production } \\
\text { Stage }\end{array}$ & $\begin{array}{c}\text { Definitions } \\
\text { of production } \\
\text { stages }\end{array}$ & $\begin{array}{c}\text { Structures representing } \\
\text { production stage }\end{array}$ \\
\hline A & $\begin{array}{c}\text { Single section } \\
\text { part }\end{array}$ \\
\hline B & $\begin{array}{c}\text { Single plate } \\
\text { part }\end{array}$ \\
\hline C & $\begin{array}{c}\text { Minor } \\
\text { assembly }\end{array}$ \\
\hline D & $\begin{array}{c}\text { Sub assembly } \\
\text { F }\end{array}$ & $\begin{array}{c}\text { Major sub } \\
\text { assembly } \\
\text { Flat plate } \\
\text { assembly }\end{array}$ \\
\hline & & \\
\hline & & \\
\hline
\end{tabular}

In the major sub-assembly production process some mounting operations take place. In the first stage a set of single section parts of 7 in number are welded together and the flat plate assembly is formed. In the second stage the flat plate assembly and a set of single section parts of 18 in number are welded together and the flat panel assembly is produced. In the third stage, the flat plate assembly, a set of minor assemblies of 14 in number and a set of sub- assemblies of 9 in number are mounted together to form the major sub-assembly being a throughput of the panel line.

\section{Process analysis of panel line workstations (Step 3)}

So far, the panel line and the structure of major subassembly as an output are briefly discussed. In this section a detailed process analysis of the panel line production system has been performed. During the process analysis each of work stations in the panel line has been considered in detail.

The main point of the process analysis is to determine the work activities. After determining work activities their operation times are calculated. Then, by considering the parallel and serial work activities, the completion times of work stations are determined. It is impossible to present here all the work activites in panel line. For this reason the process analyses of the profile spot welding (I5) and profile tig welding (I6) stations, are only exemplified in Tab. 3 and 4. 


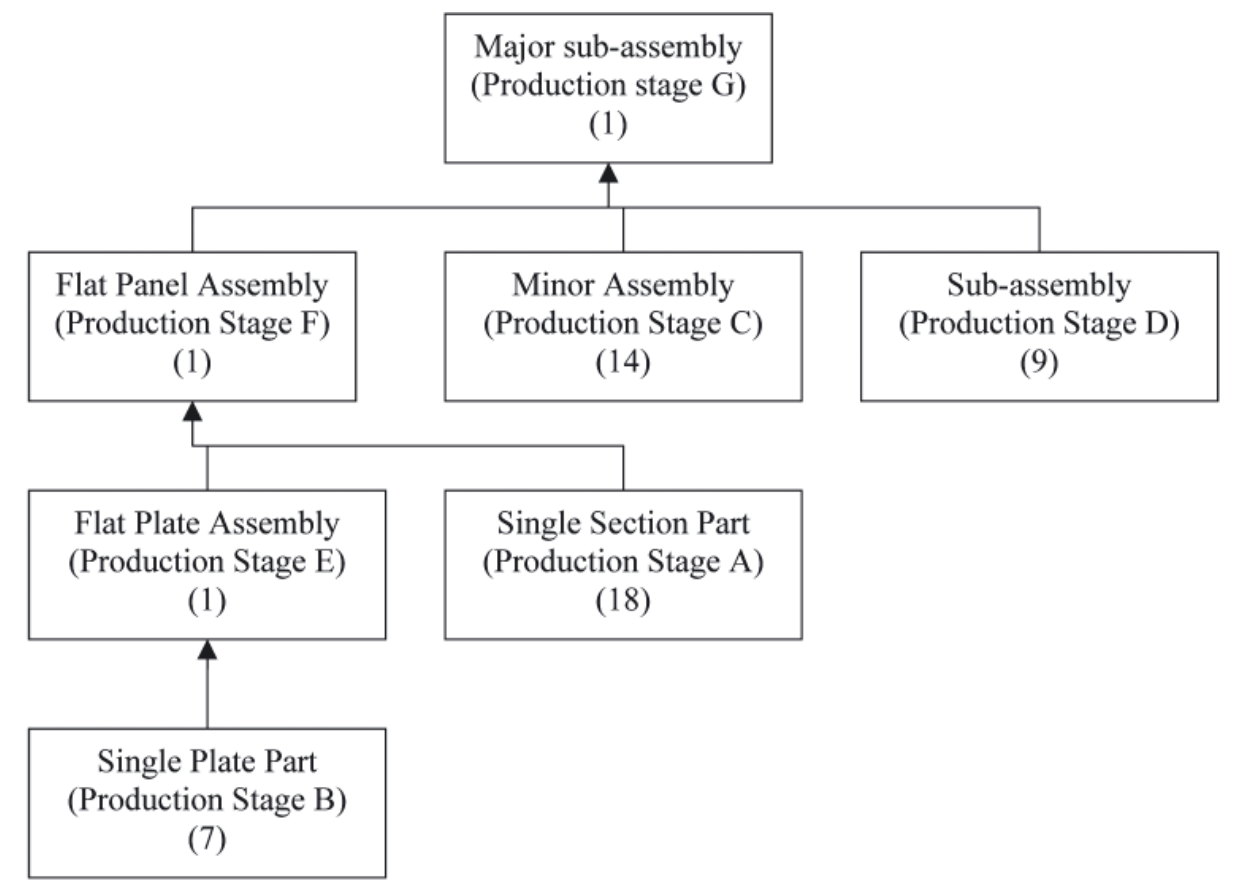

Fig. 3. Product breakdown structure of major sub-assembly

Tab. 3. The process analysis of the profile spot welding station (I5)

\begin{tabular}{|c|c|c|}
\hline $\begin{array}{l}\text { No. of } \\
\text { activity }\end{array}$ & Activity description & $\begin{array}{c}\text { Activity duration } \\
\text { time [min] }\end{array}$ \\
\hline 1 & The operator walks to the crane & 0.146 \\
\hline 2 & The operator runs the crane & 0.166 \\
\hline 3 & The crane goes to profile stock area & 8.178 \\
\hline 4 & The operator assistants go to profile stock area & 3.493 \\
\hline 5 & The crane comes down the profile & 18.051 \\
\hline 6 & The crane holds the profile & 15.2 \\
\hline 7 & The crane lifts the profile & 18.037 \\
\hline 8 & The crane transports the profile from profile stock area to the porter system & 8.473 \\
\hline 9 & The workers walk to the porter system & 3.609 \\
\hline 10 & The crane puts down the profile onto the porter system & 12.274 \\
\hline 11 & The crane leaves the profile operation area & 4.428 \\
\hline 12 & The workers settle the profile on the porter system & 3.8 \\
\hline 13 & The operator walks to the proter system & 0.118 \\
\hline 14 & The workers walk to the profile welding area & 0.404 \\
\hline 15 & The operator runs the porter system & 0.166 \\
\hline 16 & The operator drives the porter system to the welding area & 2.926 \\
\hline 17 & The operator walks to profile spot welding machine & 0.042 \\
\hline 18 & The operator cleans the welding torch & 1.5 \\
\hline 19 & The operator runs the profile spot welding machine & 0.5 \\
\hline 20 & The profile spot welding machine goes to the porter system & 44.755 \\
\hline 21 & The profile spot welding machine comes down the profiles & 3.8 \\
\hline 22 & $\begin{array}{l}\text { The profile spot welding machine transports the profile from the porter } \\
\text { system to the flat plate assembly }\end{array}$ & 46.486 \\
\hline 23 & $\begin{array}{l}\text { The profile spot welding machine comes down the profile onto the flat plate } \\
\text { assembly and alignment is performed }\end{array}$ & 111.394 \\
\hline 24 & The profile spot welding is prepared for welding operation. & 6.328 \\
\hline 25 & The process of spot welding & 63.82 \\
\hline 26 & The conveyor system transports the flat plane assembly & 1.9 \\
\hline & Total activity duration time & 380 \\
\hline
\end{tabular}


Tab. 4. The process analysis of the profile tig welding station (I6)

\begin{tabular}{|c|c|c|}
\hline $\begin{array}{c}\text { No. of } \\
\text { activity }\end{array}$ & Activity description & $\begin{array}{c}\text { Activity duration } \\
\text { time [min] }\end{array}$ \\
\hline 1 & The conveyor transports the flat panel assembly to the tig welding station & 0.574 \\
\hline 2 & The operator removes the slag from the welding torch & 38 \\
\hline 3 & The operator checks out the welding system and its connections & 38 \\
\hline 4 & The operator drives the tig welding machine to the starting point of welding & 11.577 \\
\hline 5 & The operator takes down the welding torches on the welding area & 17.1 \\
\hline 6 & The process of tig welding & 301.071 \\
\hline 7 & The operator takes up the welding torches & 3.154 \\
\hline 8 & The conveyor transports the flat panel assembly to the buffer area & 4.134 \\
\hline & Total activity duration time & 413.61 \\
\hline
\end{tabular}

Tab. 5. Completion times of the workstations of the panel line (Model 1)

\begin{tabular}{|c|c|c|c|}
\hline No. of station & Station name & Number of work activities & $\begin{array}{c}\text { Station completion time } \\
\text { [min] }\end{array}$ \\
\hline 1 & Edge cutting station & 218 & TRIA $(111.5,144.9,200.8)$ \\
\hline 2 & Edge cleaning and sequencing & 167 & TRIA $(119.2,154.9,214.6)$ \\
\hline 3 & Panel production & 327 & TRIA $(368.2,478.6,491.5)$ \\
\hline 4 & Panel cutting & 15 & TRIA $(226.1,295.5,409.1)$ \\
\hline 5 & Profile spot welding & 298 & TRIA $(174.05,227.5,233.3)$ \\
\hline 6 & Profile tig welding & 110 & TRIA $(212.7,279.3,386.7)$ \\
\hline 7 & Section spot welding & 781 & TRIA $(501,656.3,911.8)$ \\
\hline 8 & Section tig welding & 160 & TRIA $(278,361.4,506)$ \\
\hline 9 & Grinding & 148 & TRIA $(85,111.3,154.7)$ \\
\hline
\end{tabular}

Tab. 3 illustrates the work activities of the profile spot welding station. As can be seen from Tab. 3, there are 298 work activities to be perform in the profile spot welding station and its total activity time amounts to $380 \mathrm{~min}$; whereas the station completion time is only $227.5 \mathrm{~min}$ because some of the activities are parallel. That is why the total activity time and the station completion time are not same. Tab. 4 represents the work activities of the profile tig welding station. In this case 110 work activities are performed during the total activity time of $413.61 \mathrm{~min}$; whereas the station completion time amounts to $279.3 \mathrm{~min}$.

In the same way the process analysis of other workstations of the panel line are performed and the station completion times are achieved, as shown in Tab. 5.

It should be noted that the station completion times calculated from a comprehensive process analysis are regarded as optimistic ones. Because their distribution is assumed triangular, expected and pessimistic times are also needed to be assigned. In this study the optimistic and pessimistic times are assigned from gained experience.

\section{Modeling panel line by using simulation (Model 1) (Step 4)}

In this step the ARENA 11.0 software has been used for modeling the panel line. The required data have been achieved from the process analysis (Step 3); on this basis, apart from station completion times, transportation duration times are achived. The duration times are calculated by considering the production system and they are thought to have triangular distribution. Tab. 6 shows the duration times of transportation between workstations.
Tab. 6. Duration times of transportation between workstations

\begin{tabular}{|c|c|}
\hline Between workstations & Transportation times [min ] \\
\hline Arrival to I1 & $\operatorname{TRIA}(1.7,2.2,3)$ \\
\hline $\mathrm{I} 1 \rightarrow \mathrm{I} 2$ & $\operatorname{TRIA}(1.4,1.8,2.5)$ \\
\hline $\mathrm{I} 2 \rightarrow \mathrm{I} 3$ & $\operatorname{TRIA}(2.6,3.3,4.6)$ \\
\hline $\mathrm{I} 3 \rightarrow \mathrm{I} 4$ & $\operatorname{TRIA}(0.7,0.9,1.2)$ \\
\hline $\mathrm{I} 4 \rightarrow \mathrm{I} 5$ & $\operatorname{TRIA}(0.5,0.6,0.9)$ \\
\hline $\mathrm{I} 5 \rightarrow \mathrm{I} 6$ & $\operatorname{TRIA}(1.2,1.5,2.1)$ \\
\hline $\mathrm{I} 6 \rightarrow \mathrm{I} 7$ & $\operatorname{TRIA}(2.1,2.7,3.7)$ \\
\hline $\mathrm{I} 7 \rightarrow \mathrm{I} 8$ & $\operatorname{TRIA}(1.2,1.5,2.1)$ \\
\hline $\mathrm{I} 8 \rightarrow \mathrm{I} 9$ & $\operatorname{TRIA}(1.1,1.4,1.9)$ \\
\hline
\end{tabular}

In the simulation model in question, machine failures are also taken into considerations to reflect the real environment, as shown in Tab. 7. These values are not calculated but estimated. Failure times are thought to have exponential distribution.

Tab. 7. Failure times of workstations

\begin{tabular}{|c|c|c|}
\hline Station name & $\begin{array}{c}\text { Up time } \\
{[\text { min] }}\end{array}$ & $\begin{array}{c}\text { Down time } \\
{[\text { min] }}\end{array}$ \\
\hline Edge cutting station & $\mathrm{EXPO}(120)$ & $\mathrm{EXPO}(10)$ \\
\hline Edge cleaning and sequencing & $\mathrm{EXPO}(140)$ & $\mathrm{EXPO}(4)$ \\
\hline Panel production & $\mathrm{EXPO}(180)$ & $\mathrm{EXPO}(15)$ \\
\hline Panel cutting & $\mathrm{EXPO}(160)$ & $\mathrm{EXPO}(20)$ \\
\hline Profile spot welding & $\mathrm{EXPO}(130)$ & $\mathrm{EXPO}(12)$ \\
\hline Profile tig welding & $\mathrm{EXPO}(155)$ & $\mathrm{EXPO}(18)$ \\
\hline Section spot welding & $\mathrm{EXPO}(165)$ & $\mathrm{EXPO}(5)$ \\
\hline Section tig welding & $\mathrm{EXPO}(200)$ & $\mathrm{EXPO}(25)$ \\
\hline Grinding & $\mathrm{EXPO}(160)$ & $\mathrm{EXPO}(8)$ \\
\hline
\end{tabular}


In Figure 4, the simulation model of the panel line in question is presented.

Table 8 shows the module definitions of simulation model in Fig. 4.

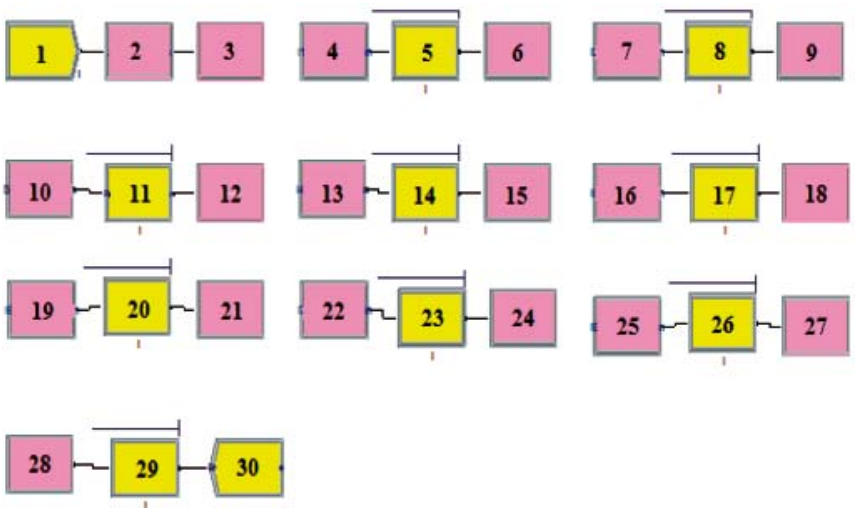

Fig. 4. Simulation model of the panel line

Tab. 8. Module definitions

\begin{tabular}{|c|c|c|c|}
\hline $\begin{array}{c}\text { Module } \\
\text { no }\end{array}$ & Module name & $\begin{array}{c}\text { Module } \\
\text { no }\end{array}$ & Module name \\
\hline 1 & Part Arrival & 16 & I5 Arrival Station \\
\hline 2 & Arrival Station & 17 & Profile Spot Welding \\
\hline 3 & Route to I1 Station & 18 & Route to I6 Station \\
\hline 4 & I1 Arrival Station & 19 & I6 Arrival Station \\
\hline 5 & Edge Cutting & 20 & Profile Tig Welding \\
\hline 6 & Route to I2 Station & 21 & Route to I7 Station \\
\hline 7 & I2 Arrival Station & 22 & I7 Arrival Station \\
\hline 8 & Edge Cleaning & 23 & Section Spot Welding \\
\hline 9 & Route to I3 Station & 24 & Route to I Station \\
\hline 10 & I3 Arrival Station & 25 & I8 Arrival Station \\
\hline 11 & Panel Production & 26 & Section Tig Welding \\
\hline 12 & Route to I4 Station & 27 & Route to I9 Station \\
\hline 13 & I4 Arrival Station & 28 & I9 Arrival Station \\
\hline 14 & Panel Cutting & 29 & Grinding \\
\hline 15 & Route to I5 Station & 30 & End of Panel Line \\
\hline
\end{tabular}

Tab. 9. The process analysis of the section spot welding station (I7) (Model 2)

\begin{tabular}{|c|c|c|}
\hline $\begin{array}{c}\text { No. of } \\
\text { activity }\end{array}$ & Activity description & $\begin{array}{c}\text { Activity duration } \\
\text { time [min] }\end{array}$ \\
\hline 1 & Transportation of matrix module structure to flat panel assembly & 15 \\
\hline 2 & Alignment of matrix module structure on flat panel assembly & 45 \\
\hline 3 & Horizontal spot welding and grinding operation after spot welding & 50.285 \\
\hline 4 & Workers go to pick up single plate parts & 0.2 \\
\hline 5 & Workers put down single plate parts & 0.2 \\
\hline 6 & Workers do alignment of single plate parts & 1.666 \\
\hline 7 & Horizontal spot welding of single plate parts & 2.826 \\
\hline 8 & Vertical fixing of single plate parts & 1.666 \\
\hline 9 & Vertical spot welding of single plate parts & 2.922 \\
\hline 10 & Operating crane & 0.083 \\
\hline 11 & Crane goes to single plate parts stock area & 8.853 \\
\hline 12 & Crane comes down onto single plate part surface area. & 12 \\
\hline 13 & Crane holds single plate parts & 6 \\
\hline 14 & Crane lifts single plate parts & 12 \\
\hline 15 & Crane transports single plate parts to flat panel assembly & 8.83 \\
\hline 16 & Crane puts down the single plate parts for marking & 12 \\
\hline 17 & Horizontal fixing of single plate parts & 4 \\
\hline 18 & Crane leaves the surface area of single plate parts & 6 \\
\hline 19 & Horizontal spot welding of single plate parts & 7.958 \\
\hline 20 & Vertical fixing of single plate parts & 4 \\
\hline 21 & Vertical spot welding of single plate parts & 9.586 \\
\hline 22 & Operating grinding machine & 1 \\
\hline 23 & Vertical and horizontal grinding after spot welding & 14.492 \\
\hline 24 & Crane goes to pick up lifting lug & 1.216 \\
\hline 25 & Crane comes down onto lifting lug's surface area & 2 \\
\hline 26 & Crane holds lifting lug & 1 \\
\hline 27 & Crane picks up lifting lug & 2 \\
\hline 28 & Crane transports lifting lug to flat panel assembly & 1.222 \\
\hline 29 & Crane puts down lifting lug on flat panel assembly & 2 \\
\hline 30 & Fixing lifting lug on panel & 4 \\
\hline 31 & Crane leaves lifting lug's surface area & 0.332 \\
\hline 32 & Spot welding of lifting lugs & 9.332 \\
\hline 33 & Crane departs from lifting lug & 2 \\
\hline 34 & Cleaning & 30 \\
\hline \multirow[t]{2}{*}{35} & Transportation of major sub-assembly & 2.528 \\
\hline & Total duration time & 284 \\
\hline
\end{tabular}




\section{Running simulation for a specified duration time and determination of panel line throughput (Step 5)}

The simulation model has been run for 10-day period under the assumption that the shipyard operates in two shifts. Each shift lasts 8 hours. Number of replication of the model is equal to 5 . As a result of the running, the panel line has produced 11 major sub-assemblies.

\section{Process analysis of section spot welding with application of module mounting (Step 6)}

When the matrix module structure is assembled on flat panel assembly, the completion time of the section spot welding station will obviously change by nature of the things. To see the effect of the changing on throughput, the new completion time of the section spot welding station should be put in the simulation model shown in Fig. 4. In the current panel line system in question the completion time of the section spot welding station is determined as shown in Tab. 5. Tab. 9 presents the work flow of the matrix module structure. When the matrix module structure is assembled on the flat panel assembly the completion time of the section spot welding station reaches $284 \mathrm{~min}$.

\section{Modeling panel line by using simulation (Model 2) and determination of panel line throughput (Step 7)}

In this step the simulation model shown in Fig. 4 is applied. All the completion duration times of the workstations remain constant except for the section spot welding station. By changing the completion time of the section spot welding station, Model 2 was obtained. The completion times of the work stations for Model 2 are shown in Tab. 10.

Tab. 10. Completion times of the workstations on the panel line (Model 2)

\begin{tabular}{|c|c|c|}
\hline $\begin{array}{c}\text { No. of } \\
\text { station }\end{array}$ & Station name & $\begin{array}{c}\text { Station completion time } \\
\text { [ min ] }\end{array}$ \\
\hline 1 & Edge cutting station & TRIA(111.5,144.9,200.8) \\
\hline 2 & $\begin{array}{c}\text { Edge cleaning and } \\
\text { sequencing }\end{array}$ & TRIA(119.2,154.9,214.6) \\
\hline 3 & Panel production & TRIA(368.2,478.6,491.5) \\
\hline 4 & Panel cutting & TRIA(226.1,295.5,409.1) \\
\hline 5 & Profile spot welding & TRIA(174.05,227.5,233.3) \\
\hline 6 & Profile tig welding & TRIA(212.7,279.3,386.7) \\
\hline 7 & Section spot welding & TRIA(284,367.4,516.9) \\
\hline 8 & Section tig welding & TRIA(278,361.4,506) \\
\hline 9 & Grinding & TRIA(85,111.3,154.7) \\
\hline
\end{tabular}

The transportation and failure times given in Tab. 6 and 7 are also valid for Model 2. When the simulation model is run for 10- day period under the assumption of two shifts, the panel line has produced 16 major sub-assemblies.

\section{Comparison of Model 1 with Model 2 (Step 9)}

Tab. 11 shows the comparison of Model 1 with Model 2 . In both the models numbers of replication, replication lengths and working hours per day are the same, whereas the numbers of major sub-assemblies are different. This difference demonstrates the effect of the module mounting on the panel line throughput.
Tab. 11. Comparison of the two applied models

\begin{tabular}{|c|c|c|}
\hline & Model 1 & Model 2 \\
\hline Number of replication & 5 & 5 \\
\hline Replication length [days ] & 10 & 10 \\
\hline Hour per day [ hours ] & 16 & 16 \\
\hline Number of major sub- assemblies & 11 & 16 \\
\hline
\end{tabular}

\section{CONCLUSION}

- In this study the simulation model has been created by determining the processes performed on the panel line. The required data achieved from the process analysis have been put in the model. The simulation model has been run for 10-day period and as a result the panel line has produced 11 major sub-assemblies. In the next step, it was assumed that the matrix module structure is assembled on flat panel assembly. In this case, the completion time of section spot welding has changed from $501 \mathrm{~min}$ to $281 \mathrm{~min}$. When the simulation model has been run in this case, the panel line has produced 16 major sub assemblies. This way the panel line produces 5 blocks more during 10 days, that means that its productivity increased by $45 \%$.

- Therefore the application of assembling matrix module structure increases the panel line productivity by $45 \%$. This is a good result in terms of shortening the ship production cycle.

\section{BIBILOGRAPHY}

1. Rashwan, A.M., and Naguib, A.:Toward improving the cost competitive position for shipbuilding yards, Part I: Impact of technology changes. Alexandria Engineering Journal, Vol.45 (2006), No.5, pp.537-543.

2. Lamb, T.: Simulation-based performance improvement for shipbuilding processes. Journal of Ship Production, Vol. 22 (2006), No. 2, pp.49-65.

3. Okumoto, Y., Hiyoku, K., and Uesug, N.: Simulation-based ship production using three-dimensional CAD. Journal of Ship Production, Vol.22 (2006), No.3, pp.155-159.

4. Shin, J.G. : a modeling and simulation of production process in subassembly lines at a shipyard. Journal of Ship Production, vol.20 (2004), No.2, pp. 79-83.

5. Shin, J.G.: a concept and framework for a shipyard layout design based on simulation. Journal of Ship Production, Vol.25 (2009), No.3, pp.126-135.

6. Alfeld, L.E., Pilliod, C.S., and Wilkins, J.R.: The virtual shipyard: a simulation model of the shipbuilding process. Journal of Ship Production, Vol.14 (1998), No.1, pp.33-40.

7. Alkaner, S. : The modeling and analysis of ship production with simulation: Case Study. PhD Thesis, ITU Institute of Science, Istanbul, 1998

8. Greenwood A.G., Hill, H.W.: Simulation optimization decision support system for ship panel shop operations. Proceedings of the 2005 Winter Simulation Conference, pp. 2078-2086.

9. Lee,D. et al. : Development and application of an intelligent welding robot system for shipbuilding. Robotics \& ComputerIntegrated Manufacturing, vol. 27 (2011)., No. 2, pp. 377-388.

10.Cha, J.H., and Roh, M.I.: Combined discrete event and discrete time simulation framework and its application to the block erection process in shipbuilding. Advances in Engineering Software, vol. 41(2010), No. 4, pp. 656-665.

\section{CONTACT WITH THE AUTHOR}

Murat Ozkok, Ph.D.

Department of Naval Architecture and Marine Engineering, Karadeniz Technical University,

61530 Camburnu/Trabzon, TURKEY, e-mail: muratozkok@ktu.edu.tr phone: +90 462752 2805, fax: +90 4627522158 